Çukurova Üniversitesi Mühendislik Mimarlık Fakültesi Dergisi, 34(1), ss. 57-66, Mart 2019

Çukurova University Journal of the Faculty of Engineering and Architecture, 34(1), pp.57-66, March 2019

\title{
Kozmetik Sanayi Atıksularının Elektro-Fenton Yöntemi ile Arıtımında Cevap Yüzey Metodu Kullanılarak Proses Optimizasyonu
}

\author{
Senem YAZICI GÜVENÇ ${ }^{* 1}$, Gamze VARANK ${ }^{1}$ \\ ${ }^{1} Y \imath l d ı z$ Teknik Üniversitesi, İnşaat Fakültesi, Çevre Mühendisliği Bölümü, İstanbul
}

$\ddot{\mathbf{O} z}$

Geliş tarihi: 06.08.2018～Kabul tarihi: 27.03.2019

Bu çalışmada, elektro-Fenton prosesi ile kozmetik sanayi atıksularından KOİ gideriminde proses parametrelerinin optimizasyonu ve matematiksel model oluşturulması için cevap yüzey metodlarından biri olan merkezi kompozit dizayn metodu uygulanmıştır. Proses değişkenleri olan $\mathrm{pH}$, akım, reaksiyon süresi ve $\mathrm{H}_{2} \mathrm{O}_{2} / \mathrm{KOI}$ oranının KOİ giderim verimleri üzerine etkileri değerlendirilmişstir. Giderim veriminin tahmin edilmesi için ikinci dereceden regresyon modelleri, Statgraphics Centurion XVI.I yazılım programı kullanılarak geliştirilmiştir. Optimum şartların belirlenmesi için varyans analizi (ANOVA) uygulanmış ve cevap yüzey grafikleri çizilmiştir. Model yardımıyla optimum şartlar; $\mathrm{pH} 4$, akım $4 \mathrm{~A}$, reaksiyon süresi 27,6 dakika ve $\mathrm{H}_{2} \mathrm{O}_{2} / \mathrm{KOİ}$ oranı 2 olarak belirlenmiş ve optimum şartlar altında KOİ giderim verimi \%86 olarak belirlenmiştir. Optimum şartlarda elektrik ve elektrot sarfiyatını içeren işletme maliyeti $6,18 € / \mathrm{m}^{3}$ olarak belirlenmiştir. Çalışma sonuçları, cevap yüzey yönteminin, kozmetik sanayi atıksuyuna uygulanan elektro-Fenton prosesinin işletme şartlarının optimizasyonu için etkili bir yöntem olduğunu göstermektedir.

Anahtar Kelimeler: Kozmetik sanayi atıksuyu, Elektro-Fenton, Cevap yüzey metodu, KOİ giderimi, maliyet analizi

\section{Process Optimization of Cosmetic Industry Wastewater Treatment By Electro- Fenton Using Response Surface Methodology}

\begin{abstract}
In this study, response surface methodology (RSM) approach using Central Composite Design (CCD) was applied to develop mathematical model and optimize process parameters for COD removal from cosmetic industry wastewater by electro-Fenton process. Evaluation of the effects and interactions of process variables; $\mathrm{pH}$, current, reaction time and $\mathrm{H}_{2} \mathrm{O}_{2} / \mathrm{COD}$ ratio were studied. Analysis of variance (ANOVA) showed the relative significance of process parameters in removal process. The second-order regression model was developed to predict the removal efficiencies using Statgraphics Centurion XVI.I software programme. The obtained optimum values via model for $\mathrm{pH}: 4$, current: $4 \mathrm{~A}$, reaction time: 27.6 min, $\mathrm{H}_{2} \mathrm{O}_{2} / \mathrm{COD}: 2$ were determined. Under optimal values of process parameters $86 \%$ COD removal efficiency was obtained. The operational cost including both electricity and the electrode consumption at optimum conditions were determined to be $6.18 € / \mathrm{m}^{3}$. Results of the study showed that RSM is a powerful tool for optimizing the operational conditions of electro-Fenton for COD removal from cosmetic industry wastewater.
\end{abstract}

Keywords: Cosmetic industry wastewater, Electro-fenton, RSM, COD Removal, Cost analysis

*Sorumlu Yazar (Corresponding author): Senem YAZICI GÜVENÇ, senem.yazici87@gmail.com 


\section{GíRiș}

Gelișen sanayi dallarına bağlı olarak oluşan atıksuların içeriğinde bulunan kirlilik parametreleri de değişiklik göstermektedir. Son zamanlarda kişisel bakım ürünlerine olan ilginin artmasıyla kozmetik ürünlerinden kaynaklanan atıksular açığa çıkmaktadır. Kozmetik endüstrisinden kaynaklanan atıksular yüksek organik madde, askıda katı madde, yağ ve deterjan içeriği ile karakterize edilebilir [1]. Ayrıca içeriğinde sürfaktan, boya ve parfüm gibi birçok organik ve inorganik madde barındırabilir. Kozmetik sanayi atıksuları BOİ/KOİ oranı düşük atıksular olduğu için klasik biyolojik arıtma ile arıtımları sınırlıdır ve yüseysel su ve yeraltı suyu kaynakları için tehdit oluşturmaktadır [2]. Kozmetik sanayi atıksularının arıtımında koagülasyon/flokulasyon, fenton, elektrokoagulasyon, elektro-fenton gibi kimyasal veya ileri arıtım yöntemleri kullanılmaktadır [1,3-5].

Temeli elektrokimyaya dayanan ve ileri oksidasyon metodu olan Elektro-Fenton prosesinde $\mathrm{Fe}$ elektrottan sisteme verilen akım yardımıyla çözünerek çözeltiye karışan $\mathrm{Fe}^{2+}$ iyonları ile hidrojen peroksitin katalizlenmesi vasıtasıyla hidroksil radikallerinin üretilmesi amaçlanmaktadır. Organik maddeleri kolayca parçalayabilen hidroksil radikalleri oldukça iyi bir oksidant özelliği göstermektedirler [6]. ElektronFenton prosesiyle hidroksil radikallerinin $\left(\mathrm{OH}^{*}\right)$ üretimi Şekil 1'de şematize edilmiştir.

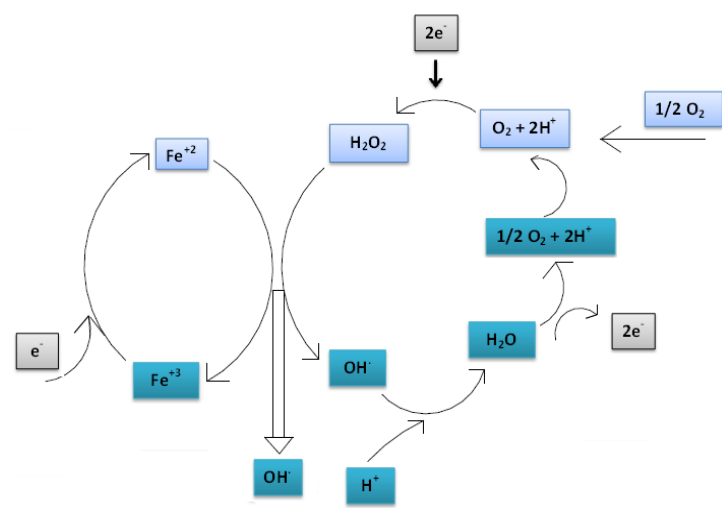

Şekil 1. Elektro-Fenton prosesle $\mathrm{OH}^{\prime}$ radikallerinin üretimi [6]
Genel olarak organik maddelerin hidroksil radikalleriyle oksidasyonu Eşitlik 1-9'da tanımlanan zincir tepkimeler vasitasıyla meydana gelmektedir:

$$
\begin{aligned}
& \mathrm{Fe}_{(\mathrm{s})} \rightarrow \mathrm{Fe}_{(\mathrm{aq})}^{+2}+2 \mathrm{e}^{-}(\text {anot }) \\
& 2 \mathrm{H}_{2} \mathrm{O}_{(\mathrm{l})}+2 \mathrm{e}^{-} \rightarrow \mathrm{H}_{2(\mathrm{aq})}+2 \mathrm{OH}_{(\text {aq })}^{-} \text {(katot) } \\
& \mathrm{Fe}^{+2}+\mathrm{H}_{2} \mathrm{O}_{2} \rightarrow \mathrm{Fe}^{3+}+\cdot \mathrm{OH}+\mathrm{OH}^{-} \\
& \mathrm{H}_{2} \mathrm{O} \rightarrow \mathrm{OH}^{\cdot}+\mathrm{H}^{+}+\mathrm{e}^{-} \\
& \mathrm{H}_{2} \mathrm{O}_{2}+\mathrm{Fe}^{3+} \rightarrow \mathrm{Fe}^{2+}+\mathrm{HO}_{2}+\mathrm{H}^{+} \\
& \mathrm{Fe}^{3+}+\mathrm{e}^{-} \rightarrow \mathrm{Fe}^{2+}\left(\mathrm{katot}^{3}\right) \\
& \mathrm{Fe}^{2+}+\mathrm{OH} \cdot \rightarrow \mathrm{Fe}^{3+}+\mathrm{OH}^{-}
\end{aligned}
$$

$\mathrm{OH} \cdot+$ organik bileşenler $\rightarrow$ ara ürünler $+\mathrm{CO}_{2}+\mathrm{H}_{2} \mathrm{O}$

$\mathrm{Fe}^{2+}+\mathrm{H}_{2} \mathrm{O}_{2}+$ organik bileşenler $\rightarrow$ ara ürünler +

$\mathrm{Fe}^{3+}+\mathrm{CO}_{2}+\mathrm{H}_{2} \mathrm{O}+\mathrm{OH}$.

Bu çalışmada kozmetik atıksuyunun karakteristiği belirlenerek ileri oksidasyon proseslerinden elektrofenton oksidasyonu ile arıtılabilirliği araştırılmıştır. Çalışma kapsamında elektro-Fenton prosesi ile kozmetik sanayi atıksularından KOİ gideriminde proses parametrelerinin optimizasyonu ve matematiksel model oluşturulması için cevap yüzey metotlarından biri olan merkezi kompozit dizayn metodu uygulanmıştır. Proses değişkenleri olan $\mathrm{pH}$, akım, reaksiyon süresi ve $\mathrm{H}_{2} \mathrm{O}_{2} / \mathrm{KOI}$ oranının $\mathrm{KOI}$ giderim verimleri üzerine etkileri değerlendirilmiştir. İlave olarak model yardımıyla belirlenen maksimum KOİ giderim veriminin elde edildiği optimum şartlarda proses maliyeti hesaplanmıştır.

\section{MATERYAL VE METOT}

\subsection{Kozmetik Sanayi Atıksuları Karakterizasyonu}

Çalışmada kapsamında kozmetik sanayi atıksu 
numuneleri kullanılmıştır. Numuneler $+4 \quad{ }^{\circ} \mathrm{C}$ sicaklikta APHA tarafindan tavsiye edilen standart metotlara göre muhafaza ve analiz edilmiştir [7]. Kozmetik sanayi atıksuyunun karakterizasyonu Çizelge 1'de verilmiştir.

Çizelge 1. Kozmetik sanayi atıksuyunun karakterizasyonu

\begin{tabular}{|l|c|c|}
\hline Parametre & Aralık & $\begin{array}{c}\text { Ortalama } \\
\text { Değer }\end{array}$ \\
\hline $\mathrm{pH}$ & $5,11-5,01$ & 5,05 \\
\hline KOİ, mg/L & $17450-17648$ & 17565 \\
\hline TAKM, mg/L & $52-65$ & 58 \\
\hline İletkenlik, mS/cm & $5,9-6,5$ & 6,3 \\
\hline Klorür, mg/L & $2896-2987$ & 2937 \\
\hline
\end{tabular}

\subsection{Deney Düzeneğinin Kurulması ve İşletilmesi}

Deneysel çalışmalar, $9 \mathrm{~cm}$ çapında ve $13 \mathrm{~cm}$ yüksekliğinde laboratuvar ölçekli pleksiglas reaktörde gerçekleştirilmiştir. 4 tek kutuplu (MP) elektrot setleri (iki anot ve iki katot elektrot) her biri $46 \mathrm{~cm}^{2}$ efektif alana sahip paralel dört demir plakadan $(6 \mathrm{~cm}$ en x $11,5 \mathrm{~cm}$ yükseklik ve $0,1 \mathrm{~cm}$ kalınlık) oluşmaktadır. Elektrotlar birbirlerinden $1 \mathrm{~cm}$ uzağa yerleştirilmiştir. Her bir deney seti için $500 \mathrm{ml}$ atıksu numunesi kullanılmıştır. Atıksu numunelerinde mevcut yeterli klorür konsantrasyonundan dolayı elektrolit çözeltisi kullanılmamıştır.

Elektro-Fenton prosesi için deneysel çalışma; $\mathrm{pH}$ 2-4, süre $10-30$ dak, $\mathrm{H}_{2} \mathrm{O}_{2} / \mathrm{KOİ} 0,5-2$ ve bir DC güç kaynağı yardımıyla 1-4 A aralığında akım uygulanması ile gerçekleştirilmiştir. ElektroFenton prosesinde çözeltinin pH'1 deneysel çalışmalar öncesinde ayarlanmış ve karıştırma işlemi için manyetik karıştırıcı (200 rpm) kullanılmıştır. Reaktöre, belirlenen miktarda $\mathrm{H}_{2} \mathrm{O}_{2}$ (hidrojen peroksit) elektrik akımı verilmeden önce ilave edilmiştir. Tüm analizler APHA standart metotlarına uygun olarak gerçekleştirilmiştir [7].

\subsection{Deneysel Tasarım}

Kozmetik sanayi atıksuyundan Elektro-Fenton prosesi ile KOİ gideriminde deneysel tasarım cevap yüzey metodu kullanılarak gerçekleştirilmiştir. Cevap yüzey metodu, hedeflenen cevapları tahmin etmek için cevaplara etki eden değişken şartlarının optimizasyonu, analizi ve modellemesi için matematiksel ve istatiksel teknikler kullanmaktadır. Cevap yüzey metodu sadece sistem ya da prosesin mekanizmasını açıklamaz ayrıca gözlemlenen sonuçlar ve kontrollü deneysel faktörlerin arasında mevcut olan ilişkilerin değerlendirmesini de sağlamaktadır [8]. Bu çalışmada cevap yüzey metodunun yaygın olarak kullanılan bir formu olan merkezi kompozit dizayn kullanılmıştır. Çalışma kapsamında, Elektro-Fenton prosesi için 4 bağımsız değişkenli ve 5 seviyeli toplam 30 deney seti ile çalışılmıştır. Dizayn, modelleme ve optimizasyon için Statgraphics Centurion XVI.I yazılımı kullanılmıştır.

Elektro-Fenton prosesinde $\mathrm{pH}\left(\mathrm{X}_{1}\right)$, $\operatorname{akım}\left(\mathrm{X}_{2}\right)$, elektroliz süresi $\left(\mathrm{X}_{3}\right)$ ve hidrojen peroksit konsantrasyonu $\left(\mathrm{X}_{4}\right)$ bağımsız değişkenler olarak, KOİ giderim verimi ise $\left(\mathrm{Y}_{1}\right)$ ise sistemin cevab1 olarak belirlenmiştir. Proses değişkenlerinin ve aralıklarının gerçek değerleri ön hazırlık deneyleri ile belirlenmiş ve Çizelge 2'de gösterildiği gibi kodlanmıştır. KOİ giderim verimleri analiz edilerek proses performansı değerlendirilmiştir.

Çizelge 2. Elektro-Fenton prosesinin optimizasyonu için bağımsız değişkenlerin kodlanmış ve gerçek değerleri

\begin{tabular}{|l|l|c|c|c|}
\hline \multirow{2}{*}{\multicolumn{2}{|c|}{ Orjinal Faktör }} & \multicolumn{3}{c|}{ Faktör Kodları } \\
\cline { 3 - 5 } & $\mathbf{- 1}$ & $\mathbf{0}$ & $\mathbf{1}$ \\
\hline $\mathrm{X}_{1}$ & $\mathrm{pH}$ & 2 & 3 & 4 \\
\hline $\mathrm{X}_{2}$ & Akım (A) & 1 & 2,5 & 4 \\
\hline $\mathrm{X}_{3}$ & Reaksiyon süresi (dak) & 10 & 20 & 30 \\
\hline $\mathrm{X}_{4}$ & $\mathrm{H}_{2} \mathrm{O}_{2}$ / KOI Oranı & 0,5 & 1,25 & 2 \\
\hline
\end{tabular}

\section{SONUÇLAR VE TARTIŞMA}

\subsection{Model Geliştirme, Regresyon Analizi ve Optimizasyon}

Merkezi kompozit dizayn, ikinci derece Eşitlikler arasında en çok tercih edilen yöntemlerden biridir. 
Kozmetik Sanayi Atıksularının Elektro-Fenton Yöntemi ile Arıtımında Cevap Yüzey Metodu Kullanılarak Proses Optimizasyonu

grafik oluşturmayı sağlayıp genişletilmiş noktaları içeren bir deneysel tasarım metodudur. Tasarım, iki düzeyli deneylerde tamamlanmış çok etkenli deneyler ya da kesirli deneyler olarak kurulabilir.

Merkezi kompozit dizayn sayesinde:

- Faktörlerin doğrusal yapısı incelenebilir,

- Faktörlerin parabolik etkileri ve faktörler arasındaki interaksiyon ve karesel ilişki incelenebilir,

- Optimum koşullar bulunabilir,

- Deneysel hata olup olmadı $\breve{g}_{1}$ kontrol edilebilir [9].

Merkezi kompozit dizayn modellemesinde, cevap değerleri doğrusal ve ikinci dereceden modellerin belirlediği faktörlere bağlı olarak, Eşitlik 10'daki gibi hesaplanır.

$\mathrm{D}=\beta 0+\sum_{\mathrm{j}=1}^{\mathrm{k}} \beta_{\mathrm{j}} \mathrm{x}_{\mathrm{j}}+\sum_{\mathrm{j}=1}^{\mathrm{k}} \beta_{\mathrm{j}} \mathrm{x}_{\mathrm{j}}^{2}+\sum_{\mathrm{i}} \sum_{<\mathrm{j}=2}^{\mathrm{k}} \beta_{\mathrm{j}} \mathrm{x}_{\mathrm{i}} \mathrm{x}_{\mathrm{j}}+\mathrm{e}(10)$

$\mathrm{Bu}$ Eşitlikde; $\mathrm{D}$ tahmini cevap, $\mathrm{x}_{\mathrm{i}}$ ve $\mathrm{x}_{\mathrm{j}}$ cevap değeri, $\beta_{0}$ sabit katsayıy1, $\beta_{\mathrm{j}}, \beta_{\mathrm{jj}}$ ve $\beta_{\mathrm{ij}}$ sırasılyla lineer, ikinci dereceden ve iki terimli etkileşim katsayılarını ve e ise hata değerini belirtmektedir [10].

Merkezi kompozit dizayn ile elde edilen deneysel sonuçların değerlendirilmesi için ikinci dereceden (kuadratik) polinom cevap yüzeyi modeli uygulanmıştır. Deneysel tasarım sonuçları baz alınarak, elektro-Fenton prosesi ile KOİ giderimi için regresyon Eşitlikleri model yardımıyla elde edilmiş ve Eşitlik 11'de verilmiştir.

$\%$ KOI Giderim $=11,666-11,326 * \mathrm{X}_{1}-8,815 * \mathrm{X}_{2}$

$+1,344 * X_{3}+50,986 * X_{4}+2,538 * X_{1}^{2}-$

$0,045 * \mathrm{X}_{1} * \mathrm{X}_{2}+0,056 * \mathrm{X}_{1} * \mathrm{X}_{3}-0,692 * \mathrm{X}_{1} * \mathrm{X}_{4}+$

$2,992 * X_{2}{ }^{2}-0,057 * X_{2} * X_{3}-0,560 * X_{2} * X_{4}-$

$0,022 * \mathrm{X}_{3}{ }^{2}-0,067 * \mathrm{X}_{3} * \mathrm{X}_{4}-10,297 * \mathrm{X}_{4}{ }^{2}$

Giderim verimlerinin tespit edildiği yukarıdaki Eşitliklerde katsayıların pozitif işareti sinerjik etkiye işaret ederken katsayıların negatif işareti antagonistik (ters sinerjistik etki) etkiye işaret etmektedir [11].
Çizelge 3. Elektro-fenton prosesi için kullanılan matris diyagram 1

\begin{tabular}{|c|c|c|c|c|}
\hline \multirow{2}{*}{ 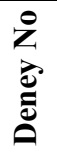 } & \multicolumn{4}{|c|}{ Faktörler } \\
\hline & pH & $\begin{array}{l}\text { Akım } \\
\text { (A) }\end{array}$ & $\begin{array}{c}\text { Elektroliz } \\
\text { süresi (dak) }\end{array}$ & $\begin{array}{c}\mathrm{H}_{2} \mathrm{O}_{2} \\
\text { dozajı } \\
\text { (Molar) }\end{array}$ \\
\hline 1 & -1 & -1 & -1 & -1 \\
\hline 2 & 1 & -1 & -1 & -1 \\
\hline 3 & -1 & 1 & -1 & -1 \\
\hline 4 & 1 & 1 & -1 & -1 \\
\hline 5 & -1 & -1 & 1 & -1 \\
\hline 6 & 1 & -1 & 1 & -1 \\
\hline 7 & -1 & 1 & 1 & -1 \\
\hline 8 & 1 & 1 & 1 & -1 \\
\hline 9 & -1 & -1 & -1 & 1 \\
\hline 10 & 1 & -1 & -1 & 1 \\
\hline 11 & -1 & 1 & -1 & 1 \\
\hline 12 & 1 & 1 & -1 & 1 \\
\hline 13 & -1 & -1 & 1 & 1 \\
\hline 14 & 1 & -1 & 1 & 1 \\
\hline 15 & -1 & 1 & 1 & 1 \\
\hline 16 & 1 & 1 & 1 & 1 \\
\hline 17 & -1 & 0 & 0 & 0 \\
\hline 18 & 1 & 0 & 0 & 0 \\
\hline 19 & 0 & -1 & 0 & 0 \\
\hline 20 & 0 & 1 & 0 & 0 \\
\hline 21 & 0 & 0 & -1 & 0 \\
\hline 22 & 0 & 0 & 1 & 0 \\
\hline 23 & 0 & 0 & 0 & -1 \\
\hline 24 & 0 & 0 & 0 & 1 \\
\hline 25 & 0 & 0 & 0 & 0 \\
\hline 26 & 0 & 0 & 0 & 0 \\
\hline 27 & 0 & 0 & 0 & 0 \\
\hline 28 & 0 & 0 & 0 & 0 \\
\hline 29 & 0 & 0 & 0 & 0 \\
\hline 30 & 0 & 0 & 0 & 0 \\
\hline
\end{tabular}

Elektro-Fenton prosesi için bağımsız işletme parametreleri incelendiğinde; KOİ giderim verimi üzerinde $\mathrm{pH}$ ve akımın negatif etkiye, elektroliz süresi ve $\mathrm{H}_{2} \mathrm{O}_{2} / \mathrm{KOI}$ oranının pozitif etkiye sahip olduğu görülmektedir.

Deneysel çalışmanın modellenmesinde kullanılan model matris diyagramı Çizelge 3 'te verilmiştir.

Deneyler sonucunda elde edilen KOİ giderim verimleri ile model yardımıyla elde edilen 
Eşitlikler ile tahmin edilen KOİ giderim verimleri ve Çizelge 4'de gösterilmektedir.

Çizelge 4. Elektro-Fenton prosesinde deneysel çalışmalar sonucu elde edilen ve model yardımıyla tahmin edilen KOİ giderim verimleri

\begin{tabular}{|c|c|c|c|c|c|}
\hline \multirow[b]{2}{*}{ 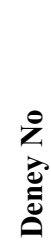 } & \multicolumn{2}{|c|}{$\begin{array}{c}\text { Cevap 1 } \\
\text { KOİ giderimi, \% } \\
\end{array}$} & \multirow[b]{2}{*}{ 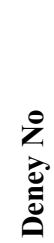 } & \multicolumn{2}{|c|}{$\begin{array}{c}\text { Cevap 1 } \\
\text { KOİ giderimi, \% }\end{array}$} \\
\hline & 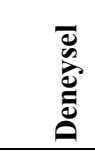 & 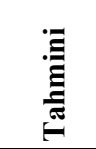 & & 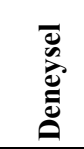 & 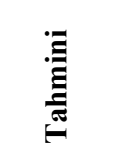 \\
\hline 1 & 30,56 & 26,68 & 16 & 83,16 & 86,18 \\
\hline 2 & 33,54 & 34,83 & 17 & 55,09 & 55,63 \\
\hline 3 & 38,5 & 42,30 & 18 & 68,29 & 63,74 \\
\hline 4 & 48,15 & 50,18 & 19 & 54,8 & 57,62 \\
\hline 5 & 33,58 & 36,49 & 20 & 76,97 & 70,14 \\
\hline 6 & 45,65 & 46,91 & 21 & 51,32 & 50,84 \\
\hline 7 & 48,82 & 48,71 & 22 & 62,6 & 59,08 \\
\hline 8 & 58,16 & 58,85 & 23 & 44,04 & 36,04 \\
\hline 9 & 59,45 & 60,62 & 24 & 62,68 & 66,67 \\
\hline 10 & 67,44 & 66,69 & 25 & 54,65 & 57,15 \\
\hline 11 & 75,84 & 73,72 & 26 & 57,88 & 57,15 \\
\hline 12 & 80,57 & 79,52 & 27 & 52,59 & 57,15 \\
\hline 13 & 71,31 & 68,42 & 28 & 56,94 & 57,15 \\
\hline 14 & 78,7 & 76,76 & 29 & 55,53 & 57,15 \\
\hline 15 & 77,54 & 78,11 & 30 & 53,3 & 57,15 \\
\hline
\end{tabular}

Şekil 2'de Elektro-Fenton prosesi ile deneysel çalışmalar sonucu elde edilen ve model yardımıyla tahmin edilen KOİ giderim verimlerinin grafiksel olarak karşılaştırılmaları verilmektedir.

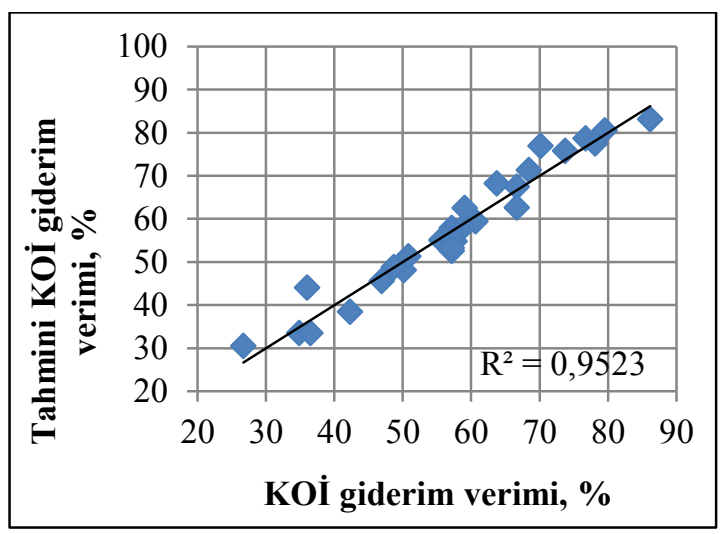

Şekil 2. Deneysel çalışmalar sonucu elde edilen ve model yardımıla tahmin edilen KOI giderim verimlerinin karşılaştırılması
Şekil 2'den de deneysel çalışmalar sonucu elde edilen ve model yardımıyla tahmin edilen KOİ giderim verimlerinin birbirine çok yakın olduğu görülmektedir. Elektro-Fenton prosesinde KOİ için grafiğin tahmin tutarlılı̆̆ $\% 95,23$ olarak tespit edilmiştir. Modelin anlamlılığı ve yeterliliği varyans analizi (ANOVA) ile gerçekleştirilmiş̧ir. Varyans analizinde cevaplar ve proses değişkenleri arasındaki ilişkiyi belirlemek için verilerin grafiksel analizi yapılmıştır. Polinomiyal modelin kalitesi $\mathrm{R}^{2}$ ile açıklanmış ve istatiksel önemi Fisher F-testi ile kontrol edilmiştir. Model terimleri F-değeri ve p-değeri ile değerlendirilmiştir. Gerçekleştirilen deney sonuçları kullanılarak elektro-Fenton prosesi ile atıksudan KOİ giderimi için elde edilen modelin regresyon parametrelerinin varyans analizi Çizelge 5'de verilmişsir.

Çizelge 5. Cevap yüzey modeli regresyon parametreleri varyans analizi

\begin{tabular}{|c|c|}
\hline Model & KOİ giderim verimi, \% \\
\hline $\mathbf{R}^{\mathbf{2}}$ & 0,9522 \\
\hline Düzeltilmiş $\mathbf{R}^{\mathbf{2}}$ & 0,9077 \\
\hline Kareler Toplamı & 5749,546 \\
\hline Kareler ortalaması & 410,6818 \\
\hline F-Değeri & 21,37828 \\
\hline Prob $>\mathbf{F}$ & 0,000000218 \\
\hline
\end{tabular}

Elektro-Fenton prosesinde regresyon Eşitliklerinin tahmin yeteneklerini gösteren $\mathrm{R}^{2}$ ifadesinin $\% 90$ 'dan fazla olması modelin $\% 95$ güven aralığında KOİ giderim verimlerinin tahmin edilmesinde yeterli olduğunu göstermektedir. Çizelge 4'te elektro-Fenton prosesiyle KOİ gideriminin varyans analizi sonucunda $\mathrm{F}$ değerlerinin sirasıly 21,37 olduğu görülmektedir. KOİ için 0,000000218 olarak belirlenen $\mathrm{p}$ değeri modelin çok anlamlı olduğunu ifade etmektedirler.

ANOVA analizinde her bir terimin anlamlılığ terimlerin karşıllı̆ı olan $F$ değeri, p değeri ve kareler toplamı vasitasiyla belirlenmektedir [12]. Büyük F değeri, karşıllk gelen terimin çok fazla anlamlı olduğunu göstermektedir. Ayrıca, F değerine bağl1 olan $\mathrm{p}$ değeri $\mathrm{F}$ değerinin yeterince büyük bir değere sahip olup olmadığını göstermek için kullanılabilmektedir $[13,14]$. 
Küçük p değeri değişkenin anlamlı olduğunu belirtmektedir. Kareler toplamı değeri, belirli bir değişkenin anlamlılı̆̆ 1 dikkate alınırken ayrıca kontrol edilmelidir [15]. Kareler toplamı değeri artarken aynı zamanda o değişkenin anlamlılı̆ı da artmaktadır [16]. Prob $>\mathrm{F}$ değerinin 0,05 'den az olduğu durumlar, model teriminin anlamlı olduğunu gösterirken, 0,1 'den daha büyük değerleri model terimlerinin anlamsız olduğunu göstermektedir [17]. Prob $>\mathrm{F}$ değeri 0,0001 'den düşük değerlere sahip olduğunda ise model istatiksel olarak çok anlamlı ve model terimleri \%95 olasılık seviyesinde anlamlıdır denilebilir [18]. Çizelge 4'deki sonuçlara proses için tanımlanan regresyonun $F$ değerinin yeterince yüksek olduğu görülmektedir. Çizelgeden 4 'ten görüldüğü üzere, modelin $\quad$ Prob $>F$ değeri 0,0001 'den daha düşük değerler almıştır.

Çizelge 6'da elektro-fenton prosesi ile KOI gideriminde cevap yüzey modeli varyans analizi (ANOVA) sonuçları verilmektedir.

Cizelge 6. Elektro-fenton prosesiyle KOİ gideriminde cevap yüzey modeli varyans analizi (Anova) sonuçları

\begin{tabular}{|c|c|c|c|c|c|c|}
\hline 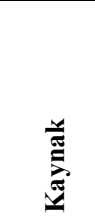 & 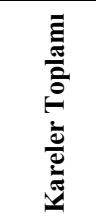 & $\stackrel{\theta}{\circ}$ & 离 & 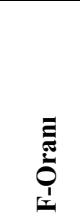 & 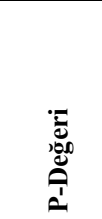 & 园 \\
\hline $\mathrm{X}_{1}$ & 295,8 & 1 & 295,81 & 15,4 & 0,0014 & $\mathrm{~A}$ \\
\hline $\mathrm{X}_{2}$ & 705,3 & 1 & 705,37 & 36,72 & $<0.0001$ & ÇA \\
\hline $\mathrm{X}_{3}$ & 305,4 & 1 & 305,45 & 15,9 & 0,0012 & A \\
\hline $\mathrm{X}_{4}$ & 4222,5 & 1 & 4222,5 & 219,8 & $<0.0001$ & ÇA \\
\hline$X_{1} X_{1}$ & 16,68 & 1 & 16,684 & 0,87 & 0,3661 & $\mathrm{Az}$ \\
\hline $\mathrm{X}_{1} \mathrm{X}_{2}$ & 0,0742 & 1 & 0,0742 & 0 & 0,9512 & $\mathrm{Az}$ \\
\hline$X_{1} X_{3}$ & 5,141 & 1 & 5,141 & 0,27 & 0,6125 & $\mathrm{Az}$ \\
\hline$X_{1} X_{4}$ & 4,316 & 1 & 4,316 & 0,22 & 0,6423 & $\mathrm{Az}$ \\
\hline $\mathrm{X}_{2} \mathrm{X}_{2}$ & 117,4 & 1 & 117,4 & 6,11 & 0,0259 & $\mathrm{~A}$ \\
\hline $\mathrm{X}_{2} \mathrm{X}_{3}$ & 11,61 & 1 & 11,61 & 0,6 & 0,449 & $\mathrm{Az}$ \\
\hline $\mathrm{X}_{2} \mathrm{X}_{4}$ & 6,363 & 1 & 6,363 & 0,33 & 0,5735 & $\mathrm{Az}$ \\
\hline $\mathrm{X}_{3} \mathrm{X}_{3}$ & 12,45 & 1 & 12,45 & 0,65 & 0,4333 & $\mathrm{Az}$ \\
\hline $\mathrm{X}_{3} \mathrm{X}_{4}$ & 4,05 & 1 & 4,05 & 0,21 & 0,6527 & $\mathrm{Az}$ \\
\hline $\mathrm{X}_{4} \mathrm{X}_{4}$ & 86,92 & 1 & 86,92 & 4,53 & 0,0504 & $\mathrm{Az}$ \\
\hline $\begin{array}{c}\text { Toplam } \\
\text { Hata }\end{array}$ & 288,1 & 15 & 19,21 & & & \\
\hline $\begin{array}{l}\text { Toplam } \\
\text { (corr.) }\end{array}$ & 6037,7 & 29 & & & & \\
\hline
\end{tabular}

$\mathrm{R}^{2}=\% 95,22 \quad(\mathrm{~A}:$ Anlaml, ÇA: Çok Anlaml, Az: Anlamsiz)
Cizelge 6'da KOİ giderimi üzerinde, akım ve $\mathrm{H}_{2} \mathrm{O}_{2} / \mathrm{KOII}$ oranının çok anlamlı bir etkiye sahipken $\mathrm{pH}$ ve reaksiyon süresinin anlamlı bir etkiye sahip olduğu görülmektedir. Anova çalı̧̧ması KOİ giderimi üzerinde, lineer katsayıların tümünün anlamlı etkiye sahip olduğunu, etkileşimli katsayıların tümünün anlamsız etkiye sahip olduğu ve kareli parametrelerden sadece akımın anlamlı bir etkiye sahip olduğunu göstermektedir. Modelin determinasyon katsayısı da modelin istatiksel anlamını onaylanmıştır. Elektro-fenton prosesinde modelin $\mathrm{R}^{2}$ değeri, KOİ için 0,952 olarak belirlenmiştir. Model $\mathrm{R}^{2}$ değerinin en az $\% 80$ değerinde olması önerilmektedir [19].

Model korelasyon katsayısı değerlerinin 0,80 değerinden yüksek olması, prosesin regresyon modelleri ile açıklanabilir olduğunu, bu çalışmada KOİ giderim verimlerini tahmin etmede uygulanan cevap yüzey modelinin kabul edilebilir yeterlilikte sonuçlar verdiğini göstermektedir.

Modelin korelasyon katsayısı değeri 0,95 olarak belirlenmiş olması, KOİ giderimi için toplam varyasyonun $\% 5$ 'inin ampirik model ile açıklanamayacağını ifade etmektedir.

Elektro-fenton prosesi ile maksimum kirletici giderimi için optimum proses parametrelerinin belirlenmesi için cevap yüzey modeli baz alınarak sayısal optimizasyon uygulanmıștır. Optimize şartlar Çizelge 7'de verilmiştir. Maksimum giderim verimleri, model yardımıla belirlenen optimum proses şartları altında gerçekleştirilen deneysel çalıșma sonucunda elde edilmiștir. Model yardımıyla belirlenen optimize şartlar altında maksimum KOİ giderim verimi \%86,31 olarak belirlenmiş̧tir.

Çizelge 7. Proses değişkenlerinin optimum işletme şartları

\begin{tabular}{|c|c|c|c|}
\hline Faktör & Düşük & Yüksek & Optimum \\
\hline $\mathrm{pH}$ & 2,0 & 4,0 & 4,0 \\
\hline $\mathrm{Akım}$ & 1,0 & 4,0 & 4,0 \\
\hline Reaksiyon Süresi & 10,0 & 30,0 & 27,61 \\
\hline $\mathrm{H}_{2} \mathrm{O}_{2} /$ KOİ & 0,5 & 2,0 & 2,0 \\
\hline
\end{tabular}


Cevap Yüzey Yöntemi, işlem değişkenlerinin deneysel uzayını incelemek amacıyla deneysel yöntemleri, prosesin cevabı ve kendisinde etkili olan bağımsız değişkenler arasındaki bağlantıyı saptamak amaciyla uygulanan ampirik modelleme metotlarını ve sistem değişkenlerinin sistemin cevabında istenilen etkiyi gösterdiği seviyelerin belirlenmesi amaciyla tercih edilen bir tekniktir [20]. Deneme setlerinden türetilen basit ampirik modellerin kullanıldığı Cevap Yüzey Metodu, günümüzde çok kullanılan bir optimizasyon yöntemidir [21].

Cevap yüzey modeli grafikleri Şekil 3'te verilmiştir. Şekil 3 'te görüldüğü gibi bir değişken merkezde sabit tutulurken diğer iki değişken belirlenen sınırlar arasında değerler almaktadır. Cevap yüzeyi ve kontür grafiği sabit tutulan bir değişken ve sınırlar arasında değerler alan iki değişkenin bir fonksiyonudur. Cevap yüzey grafikleri cevapların maksimum değerleri için optimum şartları ifade eden belirgin pik noktalarına sahip işletme şartlarını göstermektedir. $\mathrm{Bu}$ noktalardan uzaklaştıkça giderim verimlerinde azalma gözlenmektedir.

\subsection{Maliyet Değerlendirmesi}

Elektro-Fenton proseslerinde enerji tüketim miktarı ve kullanılan elektrot malzeme miktarı işletme maliyetlerinin tahmin edilmesinde önemli olan parametrelerdir. Optimum koşullar altında uygulanan proseslerin işletme maliyetleri Eşitlik 12-14 ile hesaplanmıştır.

\section{$\mathrm{OC}=\mathrm{aENC}+\mathrm{bELC}$}

Burada aENC tüketilen elektrik enerjisini, bELC ise kullanilan malzeme maliyetini ifade etmektedir. Elektrik enerjisi $\left(\mathrm{kWh} / \mathrm{m}^{3}\right) \quad$ ve elektrot tüketimlerinin $\left(\mathrm{kg} / \mathrm{m}^{3}\right)$ maliyetleri Faraday Kanunu yardımıyla hesaplanmıştır.

$\mathrm{ENC}=\frac{\mathrm{U} \times \mathrm{i} \times \mathrm{t}_{\mathrm{EC}}}{\mathrm{v}}$

$\mathrm{ELC}=\frac{\mathrm{i} \times \mathrm{t}_{\mathrm{EC}} \times \mathrm{M}_{\mathrm{W}}}{\mathrm{z} \times \mathrm{F} \times \mathrm{V}}$

Burada U hücre voltajı (V), i akımı (A), $\mathrm{t}_{\mathrm{EC}}$ işletme süresini (dak), $\mathrm{v}$ atıksuyun hacmini $\left(\mathrm{m}^{3}\right), \mathrm{M}_{\mathrm{w}}$ alüminyum ya da çeliğin moleküler kütlesini, $\mathrm{z}$ transfer edilen elektron sayısını ve $\mathrm{F}$ ise Faraday sabitini (96487 C/mol) ifade etmektedir [15]. Maliyet hesabinda proses esnasında kullanılan kimyasalların maliyetinin gözardı edilmektedir. Optimum şartlar altında KOİ giderimi için kozmetik sanayi atıksuyuna uygulanan Elektro-Fenton prosesinin işletme maliyeti $6,18 € / \mathrm{m}^{3}$ olarak belirlenmiştir.

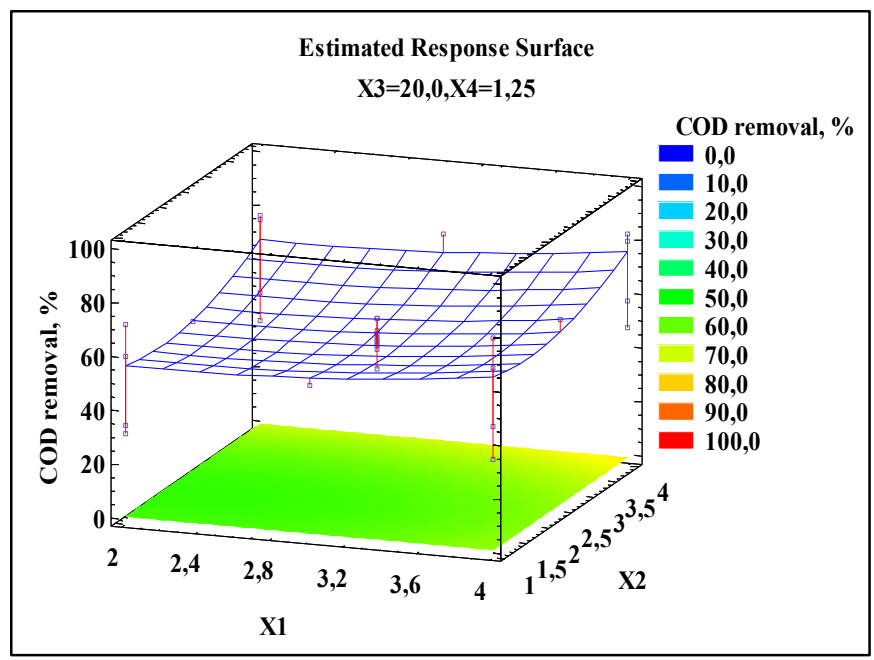


Kozmetik Sanayi Atıksularının Elektro-Fenton Yöntemi ile Arıtımında Cevap Yüzey Metodu Kullanılarak Proses Optimizasyonu
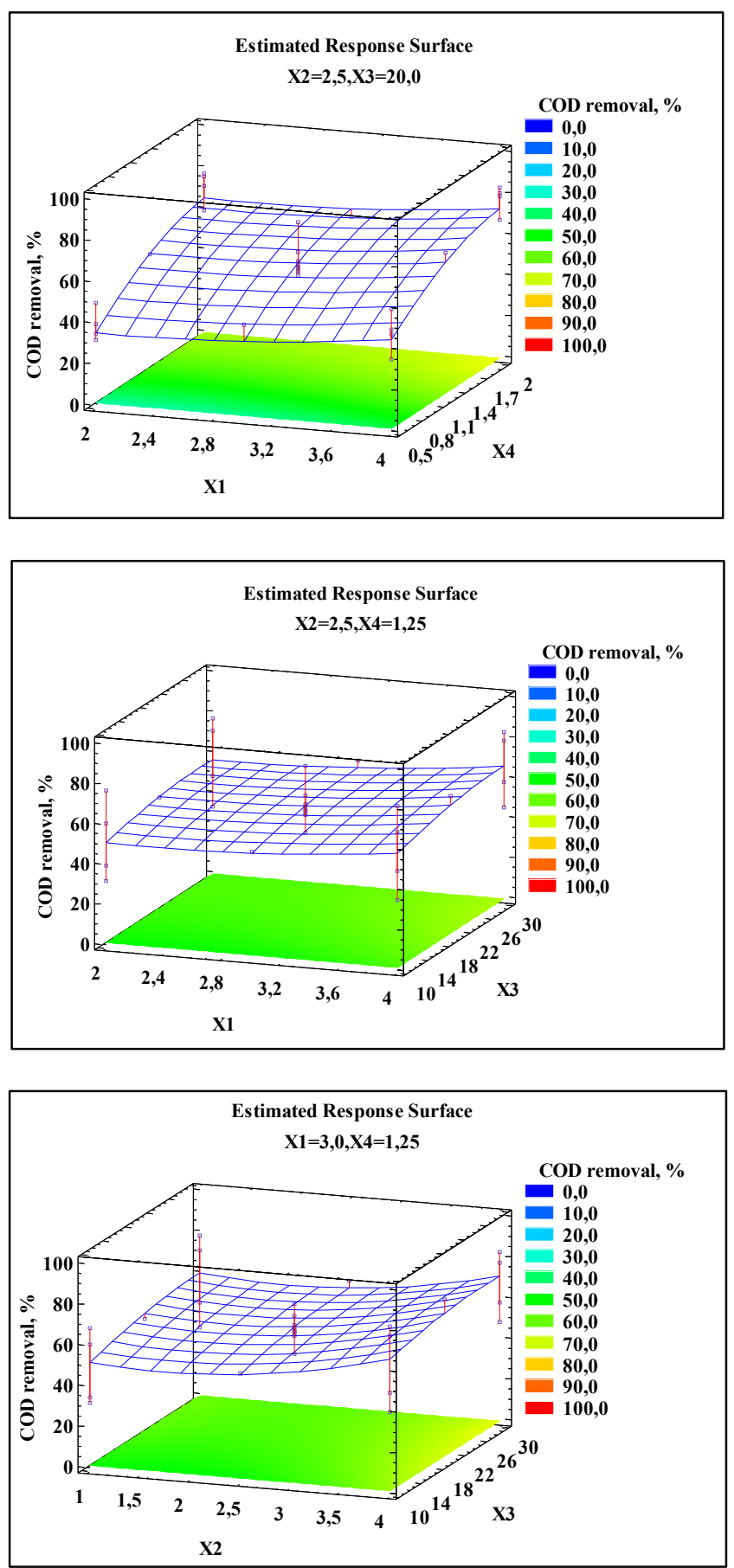

Şekil 3. Elektro-Fenton prosesi ile arıtılan kozmetik sanayi atıksuları için cevap yüzey model grafikleri, a) $\mathrm{pH}$ ve akım yoğunluğunun KOİ giderimi üzerine etkisi, b) $\mathrm{pH}$ ve reaksiyon süresinin KOİ giderimi üzerine etkisi, c) $\mathrm{pH}$ ve $\mathrm{H}_{2} \mathrm{O}_{2} / \mathrm{KOİ}$ oranının KOİ giderimi üzerine etkisi, d) Akım yoğunluğu ve reaksiyon süresinin KOİ giderimi üzerine etkisi 


\section{DEĞERLENDİRME}

Bu çalışmada, elektro-Fenton prosesi ile kozmetik sanayi atıksuyunudan KOİ giderimi gerçekleştirilmiştir. Deneysel şartları belirlemek, proseslerin performanslarını optimize etmek ve modelleme yapmak amaciyla cevap yüzey metodunun bir uygulaması olan merkezi kompozit dizayn kullanılmıştır. Çalışmada geliştirilen ikinci dereceden model, deneysel ve tahmini değerler arasında anlamlı bir ilişkinin varlığını göstermektedir. Varyans analizi yüksek determinasyon katsayılarını göstermiştir $\left(\mathrm{R}^{2}>0,80\right)$. Optimum şartlar; elektro-Fenton prosesinde KOİ giderimi için; reaksiyon süresi 27,6 dakika, $\mathrm{pH} 4$, akım $4 \mathrm{~A}$ ve $\mathrm{H}_{2} \mathrm{O}_{2} / \mathrm{KOI}$ oranı 2 olarak belirlenmiştir. Optimum şartlar altında \%95,22 KOİ giderim verimi elde edilmiştir. İşletme maliyetleri, optimize edilmiş koşullarda $6,18 € / \mathrm{m}^{3}$ olarak hesaplanmıştır. Sonuçlar elektroFenton prosesinin kozmetik sanayi atıksuyundan KOİ gideriminde etkili bir proses olduğunu ve cevap yüzey yönteminin elektro-Fenton prosesinin işletme şartlarının optimizasyonu için etkili bir yöntem olduğunu göstermektedir.

\section{KAYNAKLAR}

1. Bautista, P., Mohedano, A.F., Gilarranz, M.A., Casas, J.A., Rodriguez, J.J., 2007. Application of Fenton Oxidation to Cosmetic Wastewaters Treatment. Journal of Hazardous Materials, 143(1-2), 128-134.

2. Loraine, G.A., Pettigrove M.E., 2006. Seasonal Variations in Concentrations of Pharmaceuticals and Personal Care Products in Drinking Water and Reclaimed Wastewater in Southern California. Environ. Sci. Technol, 40, 5811-5816.

3. Aloui, F., Kchaou, S., Sayadi, S., 2009. Physicochemical Treatments of Anionic Surfactants Wastewater: Effect on Aerobic Biodegradability, J. Hazard. Mater., 164, 353-359.

4. Marcinowski, P.P., Bogacki, J.P., Naumczyk, J.H., 2014. Cosmetic Wastewater Treatment Using the Fenton, Photo-Fenton and $\mathrm{H}_{2} \mathrm{O}_{2} / \mathrm{UV}$
Processes. J. Environ. Sci. Heal A Part A, 49, 1531-1541.

5. Guvenc, S.Y., 2017. The Optimization and Modeling of PCP Wastewater Using Response Surface Methodology by Electrocoagulation Process. Desalination and Water Treatment, 63, 34-42.

6. Deliktaş, E., 2011. Kağıt Endüstrisi Atıksularının Elektro-Fenton Prosesi ile Arıtılması, Yüksek Lisans Tezi, Selçuk Üniversitesi, Fen Bilimleri Enstitüsü, Konya.

7. APHA, 2005. Standard Methods for the Examination of Water and Wastewater, APHA, 21. Edition, Washington DC, USA.

8. Ölmez, T., 2009. The Optimization of $\mathrm{Cr}(\mathrm{VI})$ Reduction and Removal by Electrocoagulation Using Response Surface Methodology, J.Hazard. Mater., 162, 1371-1378.

9. Oba, Ş., 2012. Ekstraksiyon Koşulları Optimize Edilmiş Bazı Baharat Ekstratlarının Köftenin Depolama Stabilitesi Üzerine Etkilerinin Cevap Yüzey Metodu Kullanılarak Belirlenmesi, Yüksek Lisans Tezi, Erciyes Üniversitesi Fen Bilimleri Enstitüsü, Kayseri.

10. Kasap, T., 2017. Kağıt Endüstrisi Atıksularının Peroksit İlaveli Elektrokoagülasyon Yöntemi İle Arıtımında Cevap Yüzey Yöntemi Kullanılarak Proses Optimizasyonu, Yüksek Lisans Tezi, Yıldız Teknik Üniversitesi Fen Bilimi Enstitüsü, İstanbul.

11. Lucking, F., Koser, H., Jank, M., Ritter, A., 1998. Iron Powder, Graphite and Activated Carbon as Catalysts Fort the Oxidation of 4chlorophenol with Hydrogen Peroxide in Aqueous Solution, Water Research, 32, 2607-2614.

12. Varank, G., Guvenc, S.Y., Demir, A., 2018. A Comparative Study of Electrocoagulation and Electro-Fenton for Food Industry Wastewater Treatment: Multiple Response Optimization and Cost Analysis. Separation Science and Technology, 53(17), 2727-2740 https://doi. org/10.1080/01496395.2018.1470643 (Baskıda).

13. Kumar, M., Ponselvan, F.I.A., Malviya, J.R., Srivastava, V.C., Mall, I.D., 2009. Treatment of Bio-digester Effluent by Electrocoagulation Using Iron Electrodes, J. Hazard. Mater., 165, 345-352. 
14. Amani-Ghadim, A. R., Aber, S., Olad, A., Ashassi-Sorkhabi, H., 2013. Optimization of Electrocoagulation Process for Removal of an Azo Dye Using Response Surface Methodology and Investigation on the Occurrence of Destructive Side Reactions, Chem. Eng. Process., 64, 68-78.

15.Zhang, H., Li, Y., Wu, X., Zhang, Y., Zhang, D., 2010. Application of Response Surface Methodology to the Treatment Landfill Leachate in a Three-dimensional Electrochemical Reactor. Waste Manage., 30, 2096-2102.

16. Mohajeri, S., Aziz, H.A., Isa, M.H., Zahed, M.A., Adlan, M.N., 2010. Statistical Optimization of Process Parameters for Landfill Leachate Treatment Using ElectroFenton Technique, J. Hazard. Mater. 176, 749-758.

17. Varank, G., Guvenc, S.Y., Gurbuz, G., Engin, G.O., 2016. Statistical Optimization of Process Parameters for Tannery Wastewater Treatment by Electrocoagulation and Electro-Fenton Techniques. Desalination and Water Treatment, 57, 25460-25473.

18. Guvenc, S.Y., Okut, Y., Ozak, M., Haktanir, B., Bilgili, M.S., 2017. Process Optimization Via Response Surface Methodology in the Treatment of Metal Working Industry Wastewater with Electrocoagulation. Water Science \& Technology, 75(4), 833-845.

19. Varank, G., Sabuncu, M.E., 2015. Application of Central Composite Design Approach for Dairy Wastewater Treatment by Electrocoagulation Using Iron and Aluminum Electrodes: Modeling and Optimization. Desalin. Water Treat., 56, 33-54.

20. Koç, B., Kaymak Ertekin, F., 2009. Yanıt Yüzey Yöntemi ve Gıda İşleme Uygulamaları. Ege Üniversitesi, Mühendislik Fakültesi, Gıda Mühendisliği Bölümü, İzmir.

21. Akan, G., 2013. Biyokütleden Basınçlı Piroliz Yöntemiyle Elde Edilen Ürünlerin Cevap Yüzey Metodu Kullanılarak Optimizasyonu ve Karakterizasyonu. Yüksek Lisans Tezi, Anadolu Üniversitesi, Fen Bilimleri Enstitüsü, Kimya Mühendisliği Anabilim Dalı, Eskişehir. 